A CASE OF

\section{AMOEBIC DYSENTERY WITH ABSCESS OF THE LIVER}

IN A PATIENT WHO HAD NEVER BEEN OUT OF ENGLAND.

[With Special Plate.]

\section{BY}

ROBERT SAUNDBY, AND M.D., LL.D., F.R.C.P., SENIOR PHYSICIAN, BIRMINGHAM GENERAL HOSPITAL.
JAMES MILLER, B.Sc., M.D.ED., M.R.C.P.ED. PATHOLOGIST TO THE HOSPITAL.
Report of Case.

W., aged 42, cycle-rim maker, was admitted into the General Hospital on November 21st, 1908, complaining of pain in the stomach and at the bottom of the back, which had lasted a week. On inquiry from his wife and his brother it was ascertained definitely that he had never been away from the Birmingham district, but for some weeks he had complained of liver pains, by. which he had not appeared to be much inconvenienced. He said his bowels were open freely two or three times a day.

Condition on Admission.

He looked extremely ill, and was perspiring freely. His face showed many dilated veins. Temperature $102.4^{\circ}$, pulse 104, respirations 28. His tongue was covered in the centre with a brownish glaze, but was moist at the edges; his abdomen was distended; his respiration was jerky, and on taking a deep breath he complained of pain below and to the right of the umbilicus. There was no eruption. The liver dullness was not increased; the spleen could not be felt; the heart was not enlarged, sounds normal. The left side of the chest was normal, except for some crepitations at the base; on the right side there was dullness with diminished breath sounds, and absent tactile vocal fremitus at the base; on exploration with a needle no fluid was obtained. Widal reaction negative.

After-History.

Four days after admission he passed a stool containing a considerable quantity of blood. The dullness and diminished breath sounds on the right side extended gradually nearly up to the spine of the scapula, and on November 27th, on exploring with a needle, some bloodstained serum was withdrawn and $15 \mathrm{oz}$. of fluid were removed. This fluid was blood-stained and contained pus cells. Pulse 120, respirations 32 to 36 . There had been no more diarrhoea; in fact, the bowels only acted after enemata. On November 30 th he became suddenly worse, and died in the afternoon.

\section{Post-mortem Examination.} Heart.

The heart weighed '11 oz, and was enlarged, ovoid in shape; area of thickened epicardium on anterior surface of left ventricle; right auricle dilated, wall thickened. Right auriculo-ventricular valve admitted three fingers easily and appeared healthy. Right ventricle filled with yellow clot; its wall thickened. Left auriculo-ventricular valve admitted two fingers and showed chronic thickening. Aorta and coronary arteries healthy.

\section{Lungs.}

Right 23 oz., left $18 \mathrm{oz}$. Right pleural cavity contained 1 pints of slightly blood.stained fluid. Right lung bound down to diaphragm by fairly recent adhesions; the lung Fis collapsed, and there was a calcareous nodule in the woer lobe. Left lung free from pleurisy; on section con Ited; two small calcareous nodules in the upper lobe; o tabercle in bronchial glands.

\section{Abdomen:}

No excess of fluid in the peritoneal cavity. Recent Thesions in the right iliac fossa which limited an abscess mond the head of the caecum. Stomach and small intesthowed nothing of note. Caocum and large intestine wended and walls thickened. The blind end of the caecum communicated by ruptare with the abscess cavity in the right iliac fossa, but the opening was plugged by a slough. On opening the gut a large ulcer with black adherent slough was seen to occupy the caput caecum coli. Passing upwards along the ascending colon there were other smaller alcers, most of - which were about the size of a small pea; their margins were raised and overhanging, and their floors were occupied by firmly adherent sloughs (Fig. 1). There were also numerous small nodules in the submucous coat of the bowel opening by minute apertures on the surface. These appearances were visible throughout the transverse colon, but faded away in the descending part. The contents of the bowel were black and tarry. The appendix was enlarged but not ulcerated. The mesenteric glands were enlarged, pale, and firm.

Liver.

One hundred and two ounces. In removing the organ an abscess 5 in. in diameter was opened; it contained brownish-red pus and masses of necrosed liver substance. The abscess was bounded posteriorly by the diaphragm and the abdominal wall; it was about the size of a fetal head (Fig. 2). The liver in the vicinity was pale and necrotic.

\section{Kidneys.}

Right $7 \frac{1}{2}$ oz., left $9 \frac{1}{2}$ oz. Both organs were soft and flabby; the cortices enlarged and pale, but the capsules were non-adherent.

\section{Spleen.}

Nine and a half ounces, enlarged, pale; and soft. Cultares in broth and in agar were made from the ulcers in the large bowel and from the contents of the liver abscess. The former showed streptococci, the latter proved sterile.

\section{Microscopical Examination.}

Sections of the large bowel show as their most conspicuous feature a uniform thickening of the submucous coat, which is partly due to the increase of the fibrous tissue, but in part also caused by exudation of fibrin and cells. There is diffuse catarrhal inflammation of the mucons membrane. The smaller ulcers represent flask. shaped excavations in the submucous coat (Fig. 3), their margins are raised and are formed by overhanging mucous membrane which is the seat of advanced catarrhal change; the floor is formed by the outer portion of the submucous coat, and the centre is occupied by a slough composed of necrotic tissue, inflammatory cells and exudate with occasional amoebae.

Other micro-organisms were not as a rule to be found in these ulcers except in the more superficial parts. The tissues around showed a considerable amount of infiltration with leucocytes and fibrin. Amoebre could be seen, but they were not numerous in the neighbourhood of the smaller ulcers. These ulcers seem to develop as a lesion of the mucous membrane, as in all the areas of necrosis examined by us. we have invariably found a breach of the mucous membrane, although it might be scarcely larger than a pinhole. Dopter has described three stages in the process of the formation of these ulcers: (1) Stage of catarrhal inflammation; (2) pre-ulcerative stage characterized by necrosis of an area of the mucous membrane and submucous coat; (3) stage of ulceration. This description is in accordance with the facts as observed by us.

The larger ulcers extend, as a rule, to the muscular coat their margins are formed by necrotic tissue containing the débris of inflammatory cells and fibrous tissue, with numerous bacteria and amoebae. Passing beyond the zone of necrosis amoebae become more numerous, and inflam. matory cells of various kinds may be found. Many of the latter are large, round, and vacuolated, and are often difficult to distinguish from amoebae. Such cells are probably chiefly endothelial in origin. Another type of cell which is found in large numbers is,oval, with branched processes and a single nucleas, its protoplasm containing large numbers of strongly basophilic granules.

The lymphatics and blood ressels in the neighbous hood of the alcers were dilated, and the endothelial cells lining them were swollen.

The Amoeba.

The amoebae could be demonstrated by any staining method, but the following gave the best results: Stain section in carbol-thionin blue for eight or ten minates 
wash in water, then repidly in 1 per cent. acetic acid in water; wash again in water, dehydrate; clear in xylol, monnt. By this method the amoebae may be distinguished from, other cells by their deeper purple colour, as in Mallofy's method. When they are properly stained, the ampobae appear,as circular or sometimes irregularly shaped cells with finely granular protoplasm containing numerous 7qucioles (Fig. 4). They sometimes contain basophilic granules, but rarely show other inclusions, and, although gome were in close contact with streptococci, we have never seen the latter inside them. The nucleus may or may not be visible, but when present it varies mach, in shape, size, position, and staining reaction. The amoebre were most numerous in the tissues immediately surrounding the ulcers in the submucous and muscular coats, in the tissue spaces, in the lymphatics and blood vessels. The truth that the amoebae were actually invadiing the tissues is demanstrated by the position in which they were found, and also by the fact that not infrequently they have been fixed in the act of projecting their psendopodia (Fig 5). They were also found in the sloughs, but, so far, we have failed to see them in the glandular acini. Numbers of other organisms-streptococci and bacilli-were found in the more superficial parts of the sloughs.

The enlarged mesenteric glands showed catarrh of their sinuses, and overgrowth of fibrous tissue, but no amoebae were found in them.

The liver showed a widely-distributed increase of fibrous tisste around the portal tracts, which are also infiltrated with inflammatory. cells. As the neighbourbood of the abscess was approached areas of necro sis were to be observed but they : were not especially associated with the central veins as described by Councilman; in these areas the place of the degenorated liver cells was taken partly by dilated capillaries, partly by young fibrous tissue, and they resembled very closely the red areas met with in acute yellow atrophy. Many of the vessels (chiefly the veins) were throm

bosed, the thrombi being found in all stages of organiza tion. In the neighbourhood of the ... abscess the columns of 'liver cells were flattened, and showed all stages of degeneration. "Amoebre could be seen in close contact with fairly healthy liver cells (Fig. 6), and also inside the blood vessels and bile ducts (Fig. 7). The contents of the abscess consisted of strands of fibrous tissue, necrosed liver cells, leucocytes, both lymphocytes and polymorphs, and amoebae. Councilman did not find polymorphs in the liver lesions in his cases, and he considers that a pure amoebic lesion does not attract such leucocytes. Certainly at the spreading margin of the abscess these cells were not present in excess, and there was no evidence that amoebae were attacked by them, but deeper in the abscess, where degeneration and liquefaction of cells were in process, they were numerous.

The amoebae in the liver lesions showed characters similar to those in the ulcers, but cell inclusions were more frequently present. There were at least three types.

The first type consisted of fine granules fairly uniform in size, and not suggestive of pieces of ingested chromatin; it is not impossible that these may be the chromidia described by Schaudinn and by Lesage as the first step in the formation of a capsule for the resting stage of the organism. Schaudinn only observed the development of these resting forms in the living subject during the healing of the lesions, but doubtless they are also formed under disadrantageous conditions in the tissues at any time, although Wenyon has not observed them.

The second type of inclusion was a comparatively large nound or sausage-shaped body, with well-defined margins (f.ig. .8), which took on basic stains very deeply; these may possibly be chromatin or other products of cell degeneration, but they have not the appearance of the usual chromatin inclusions of phagocytes.

Thirdly, we observed the thin rod-shaped bodies which have been described by Councilman as curiously like tubercle bacilli; we make no suggestion as to their nature.

In support of the view that resting forms occur, we may say that we frequently met with rather small amoebae with well-defined, darkly stained margins, which gave the impression of being enclosed in a somewhat opaque envelope (Fig, 9).

The chief points of interest from a pathological point of view in the case are:

1. Ulcerative colitis, in which the smaller ulcers are circular and flask-shaped-bouton de chemise of French authors-with overhanging edges and relatively small circular openings into the lumen of the bowel and adherent sloughs; one of the larger ulcers had perforated into the peritoneal cavity.

2. The presence of an enormous abscess in the posterior part of the liver, the pus of which gave no growth on inoculating in ordinary media.

3. Lastly and most important, the presence of amoebae in the ulcers and the liver abscess and in the tissues around these lesions.

We believe we are warranted in concluding that the pathogenic organism in this case is the Entamoeba histolytica (Schaudinn), and that the case is one of amoebic dysentery with consecutive liver abscess, of the type which we are accustomed to call "tropical" dysentery. The appearance of the ulcers alone is sufficient evidence : of the nature of the condition. If this be admitted, and as the patient had never been out of England, or, indeed, away from the Birmingham dis trict, the case.presents a peculiar interest, inasmuch as, so far as we have been able to ascer. tain, it is the first obser. vation of the kind which has been recorded in Great Britain. Juergens has mentioned a case which occurred in Berlin, and Caussade and Joltrain have recorded one from Paris, while Kartulis (1906) has stated that Scandinavia, Great Britain, Spain, and Portugal are the only European countries from which cases of amoebic dysentery have not been reported. Davidson (1908) remarks that the disease has not been recognized, but is, perhaps, not entirely absent from England.

The next point of interest is how did the individual become infected? The medium of infection in dysentery is, as with typhoid fever, usually water, less frequently food contaminated by dust or flies. Given a case of tropical dysentery-that is, dysentery acquired in the tropics-in the neighbourhood of the patient (and such cases are from time to time imported into England) we have a source of possible infection from which contamina tion of food or drink during warm weather is all that would be required for the communication of the disease.

The perforation of the caput caecum coli is worth noting, as Kartulis describes its occurrence, but indicates that it is infrequent. The distribution of the ulceration was probably that most frequently seen-that is to say, it was most marked in the caecum, extending thence as far as the descending colon, but becoming progressively less marked. The size of the liver abscess indicates that it had been in existence some time, and, in fact, everything points to the disease having run a chronic course without marked constitutional symptoms.

Owing to the latter circumstances, the clinical history is deficient. The nature of the case was not recognized during life; it was regarded as a septic fever of unknown origin with haemorrhagic purulent pleurisy. The patient made no complaint referring to the liver after his admission to the hospital, but the failure to recognize enlargement of the organ was probably due to the 
MARCH 27, 1909.] PROFESSOR SAUNDBY AND DR. MILLER ON AMOEBIC DYSENTERY. [

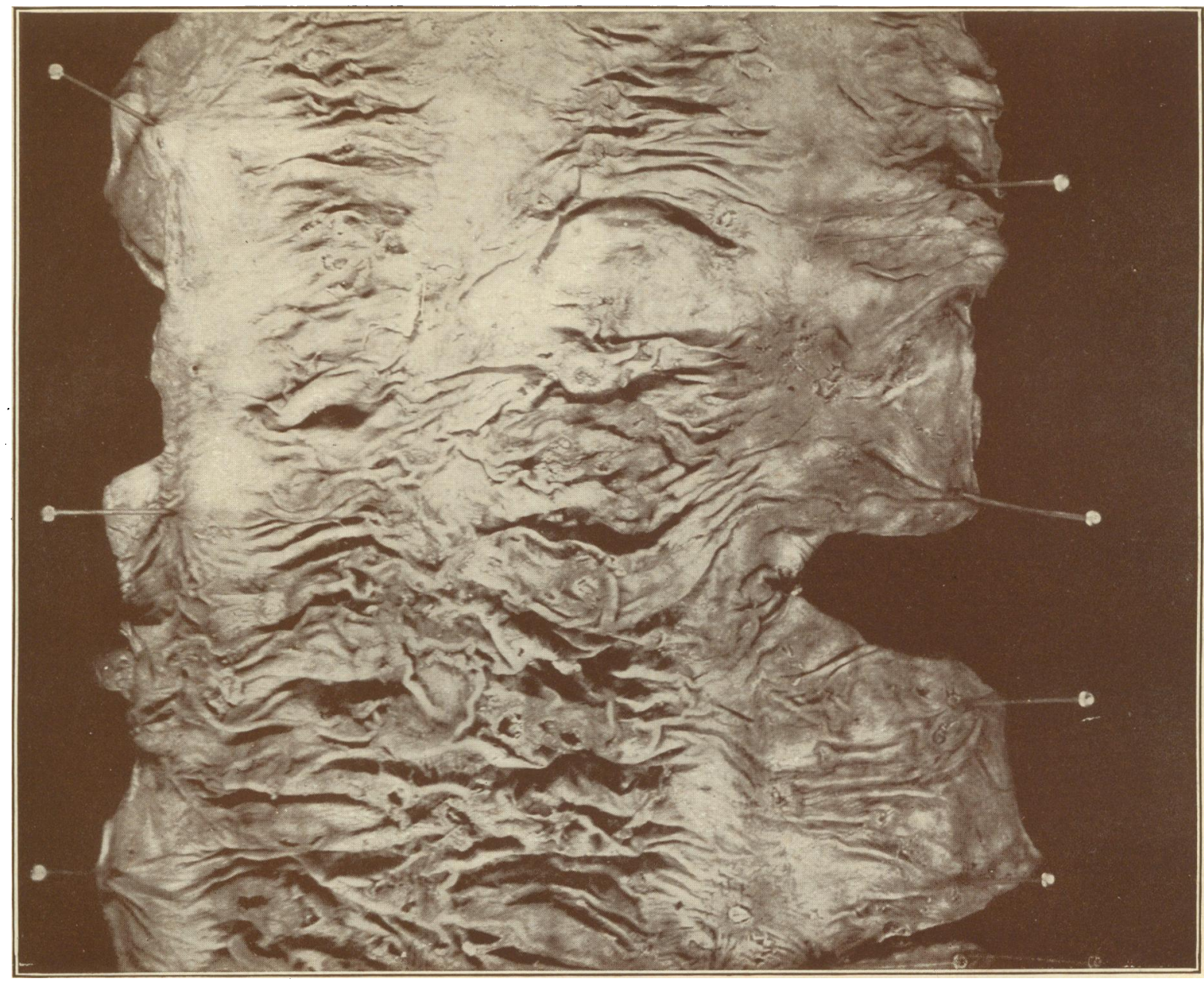

Fig. 1.
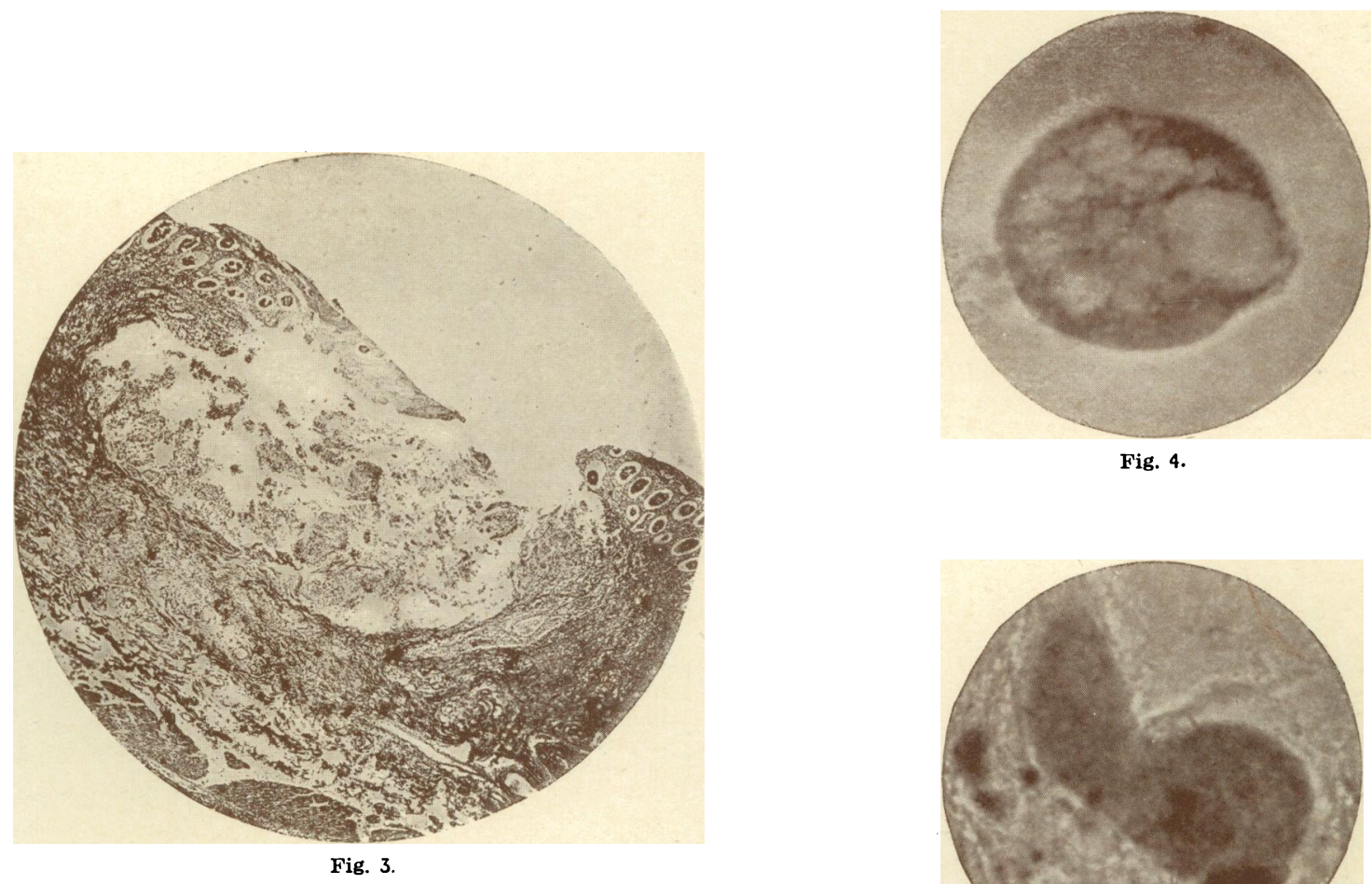

Fig. 4.

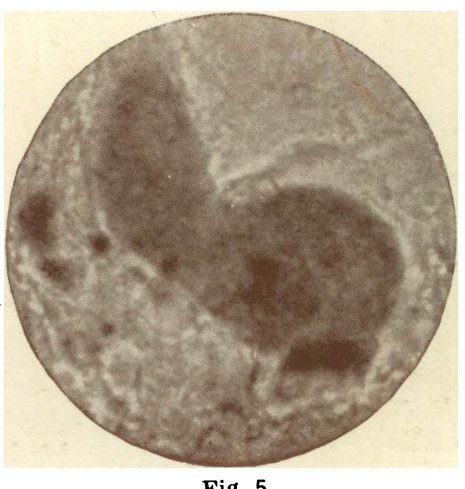

Fig, 5 
$\underset{\text { MEDICAL JOURNAL }}{\text { THR BRTrRB }}$ PROFESSOR SAUNDBY AND DR. MILLER ON AMOEBIC DYSENTERY. [MARCH 27, I9O9.

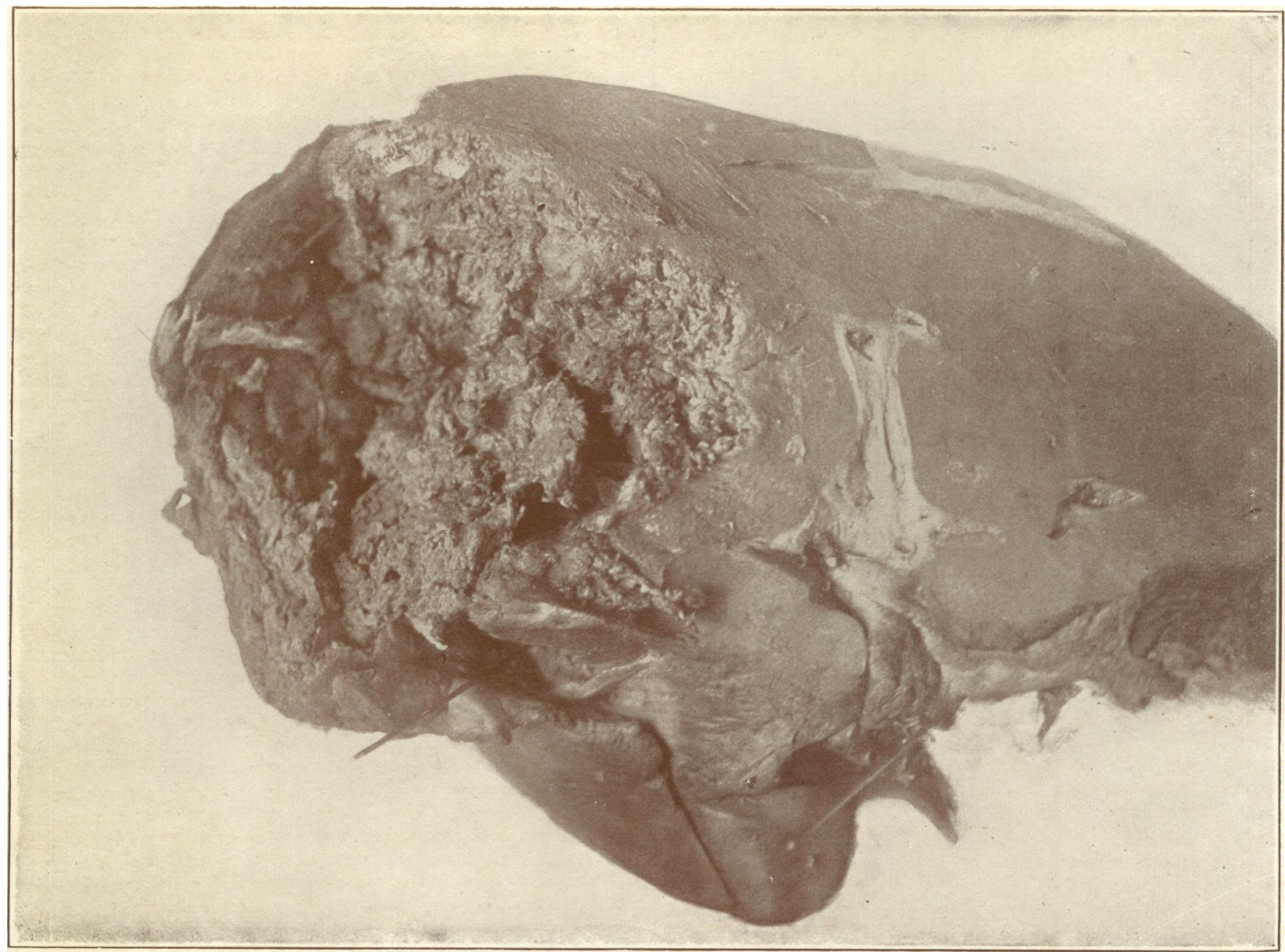

Fig. 2.

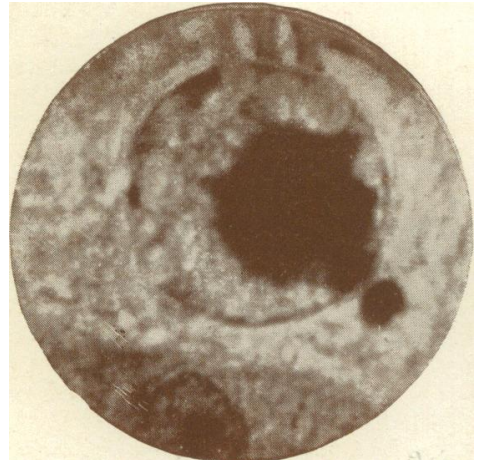

Fig. 6.

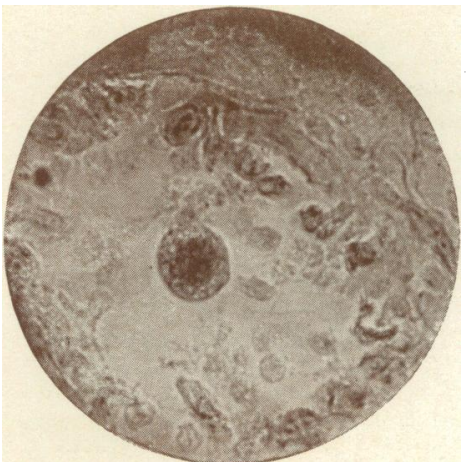

Fir. 7.

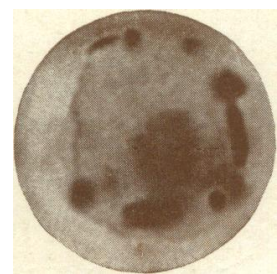

Fig. 8.

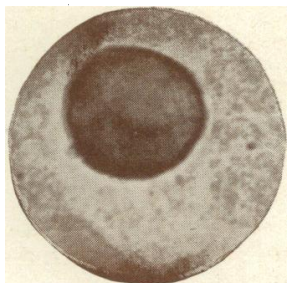

Fig. 9. 
distension of the bowel. Although he gave a history of his bowels having been freely open before admission, he did not speak as if he had been troubled by diarrhoea, and after his admission the bowels only acted with enemata. Haemorrhage from the bowel occurred only once, but was profuse. Strong regards this symptom as a rare occurrence in dysentery, and in the cases in which he met with it he has, he says, generally found it associated with abscess of the liver. He speaks of it as being of peculiarly fatal prognostic significance, and in this case death fol. lowed in a very few days. He believes that the reason bleeding does not take place more often is because the arteries are commonly thrombosed or are the seats of more or less marked endarteritis. The immediate cause of death was no doubt heart softening, as there was no general peritonitis.

Although the connexion between abscess of the liver and dysenteric ulceration has been well known for many years, attention has been drawn in recent times to the want of harmony between the statistics of the two diseases. This is probably explained by the special connexion between the amoebic form of dysentery and hepatic suppuration. Bacillary dysentery is the more common, and more often occurs in epidemics, and is more likely to attack people whose habits and circumstances are insani. tary, as is the case with natives in India, among whom dysentery is much more common than among Europeans. Yet, on the other hand, Europeans are more liable to abscess of the liver, as, according to Buchanan, the ratio was in natives 1 abscess to 628 cases of dysentery, and in Europeans 1 to 18 . We have no figures that enable us to say what is the actual proportion of ab. scesses occurring in amoebic dysentery, because there are no statistics which distinguish between the two forms; if we had them we might be able to determine this point, but-many observers have pointed out the relative rarity of abstess in bacillary dysentery. Any cause which gives rise to congestion of the liver would favour the occurrence of abscess, and there

fore we may expect to see it in those persons who live sedentary lives, indulge freely in alcohol and in the other pleasures of the table; this in effect is the case. It is more common amongst Europeans than amongst natives, comparatively rare amongst European women and children, more often met with in rich natives than in poor seldom met with in total abstainers, and according to Sandwith is only seen in those natives of Egypt who are addicted to alcohol. The patient in the present case had all the appearance of a man who had abused alcohol.

The occurrence of a case of amoebic dysentery in England must be accepted as a rarity and an event which must be only exceptional. As amoebae readily die at temperatures below $75^{\circ} \mathrm{F}$, the conditions must be unusual which permit of their survival outside the body. Hence, in all probability, the disease, although no doubt imported into this country from time to time, rarely spreads; that it may do so, however, when circumstances favour it, seems to be established by the present case.

Caussade et Joltrain; Bull. et Mém. Soc. Méd. des Hôp. de Paris. 1507. xxiv, p. 167

Councilman and Lafleur: Johns Hopkins Hospital Reports, ii, 1891, p. 395.

Davidson: Allbutt's System of Medicine, 1908, vol. ii, pt. 2, p. 527.

Dopter: Arch. de Mied. Expér., 1907, xix, p. 505

Kartulis: Handbuch der path. Mikr. Kolle u. Wassermann, 1907. Ergänzungsband, i, S. 347

Lesage: Annales de l'Institut Pasteur, 1905, Tome xix, p. 9

Schaudinn : Arb. aus dem Kaiser-Gesundheitsamt. 1903, xix, s. 547.

Wenyon: British Medicat Jodrnal, 1908, ii, p. 1245.

ST. JoHN's HospitaL, Morden Hill, Lewisham, is the recipient of a bequest of $£ 1,000$ under the will of the late Miss Betsey Ann Burton Williams of Lee, Kent, whose will has now been proved.

\section{BILHARZIOSIS OF WOMEN AND GIRLS IN EGYPT IN THE LIGHT OF THE} "SKIN-INFECTION THEORY."

By Dr. A. LOOSS,

PROFESSOR OF PARASITOLOGY, SCHOOL OF MEDICINE, CAIRO.

In the British Medical Journal of October 31st, 1908, page 1355, Mrs. B. S. Elgood, Assistant Medical Officer, Education Department, Egypt, published a very interest. ing article on Bilharziosis among Women and Girls in Egypt. Whereas before nothing definite had been known, and many had even thought that bilharziosis was rare among the women in Cairo and other towns of Egypt, Mrs. Elgood proves the contrary. An examination of the urine of the girls of two middle-class schools in Cairo revealed the fact that, out of 40 girls aged 12 to 16 of one school, 11-that is, a percentage of 27.5-were infected. In the second sthool, attended by 79 girls aged 6 to 13 , 39 girls were boarders; among them, 8-that is, a percentage of 20.5-showed bilharzia eggs and blood in their urine; the other 40 girls were day pupils; among them, 11-that is, a percentage of 27.5 -were infected. After these results obtained from girls, the author was very much surprised to find an almost total absence of infection in adult women; among 62 female patients of the Kasr-el-Ainy Hospital, consisting of the respectable' lower midale classes from all parts of Egypt, only 2, or a percentage of 3.2, were found to void bilharzia ova. In her own eight years' practice among women in Egypt, the author says that she has never been consulted by an adult for bilharziosis, and that in spite of frequent examinations of urine for other purposes, she only once accidentally found bilharzia eggs.

Thus far the results of Mrs. Elgood's investigations form indeed a very valuable addition to our knowledge of the distribu. tion of bilharziosis among the inhabitants of Egypt. Until within the last few years the disease had appeared to be practi cally confined to the male population of the rural districts for the most numerous and the most severe cases observed had all been peasants, among whom no age, except the years of early boyhood, seemed exempt. Infection of women was, to judge from the hospital records, comparatively rare, even in the country. With regard to the peasant women, the researches of Moh. Bey Talaat, undertaken in loco, elicited the interesting difference that the percentage of those affected was greatest among the poorest, whose women-folk work in the fields together with, and in the same fashion as, the men, and that it was lowest, or practically nil, among the best situated, whose women do not take any part in the field work of their male relatives. The native population of the towns had during all this time appeared to be generally free from infection, for no cases from towns had come under observation in the hospitals. Here, the researches of Engel, Kautsky, and others brought about a change; it was shown by these authors that in Cairo the adult men are indeed for the most part free, or show only traces of old infections, but that boys may have bilharzia eggs in their urine in as high a proportion as 80 per cent. of the cases examined. In many of these boys no external symptoms of the affection were noticed. This general picture of the distribution of bilharziosis among the native population of Egypt is completed, in a most instructive manner, by Mrs. Elgood's observations, which show that what had been known about men is to a very large extent valid also for the women of Cairo in particular, but undoubtedly of other towns of Egypt as well.

In addition to her actual observations, Mrs. Elgood makes some inquiries into the previous history of her cases, and thus collects a number of facts which she thinks throw light on the mode of infection. Since it 